\title{
HORTAS URBANAS E PERIURBANAS: CONTRIBUIÇÕES PARA O DESENVOLVIMENTO DE UM ESPAÇO URBANO SUSTENTÁVEL
}

\author{
URBAN AND PERIURBAN VEGETABLES: CONTRIBUTIONS TO THE \\ DEVELOPMENT OF A SUSTAINABLE URBAN SPACE
}

\begin{abstract}
Luisa Motta Klöckner
Universidade Regional do Noroeste do Estado do Rio Grande do Sul, RS, Brasil E-mail: luiza.
\end{abstract} klockner@sou.unijui.edu.br

\section{Tarcisio Dorn de Oliveira}

Universidade Regional do Noroeste do Estado do Rio Grande do Sul, Ijuí, RS, Brasil E-mail: tarcisio_dorn@hotmail.com

DOI: https://doi.org/10.46550/amormundi.v1i1.9

Recebido em: 23.09.2020

Aceito em: 28.10.2020

\begin{abstract}
Resumo: A globalização gerou uma massificação de produtos, sabores e culturas, causando a exclusão do meio rural e do "saber fazer" do agricultor. Ao passo que a populaçấo nas áreas urbanas apenas aumenta no decorrer dos anos, o fornecimento de alimentos, oferta de empregos e preservação ambiental se tornam problemas crescentes. No campo da alimentação, o processo de desterritorialização e de perda de saberes é percebido com a naturalização de práticas como a pasteurização dos sabores e o desaparecimento de inúmeros alimentos, contribuindo para a degradação do meio ambiente. Há muito se fala em revolução verde e sustentabilidade. Dessa forma, este trabalho tem por objetivo principal, apontar as contribuiçóes do incentivo a implantação de hortas urbanas e periurbanas para o desenvolvimento sustentável e, consequentemente, produzir um ambiente mais verde e mais saudável.
\end{abstract}

Palavras-chave: Horta Urbana. Desenvolvimento Sustentável. Sistemas Agroalimentares Sustentáveis. Espaço Urbano.

\begin{abstract}
Globalization has generated a massification of products, flavors and cultures, causing the exclusion of the rural environment and the "know-how" of the farmer. As the population in urban areas only increases over the years, food supply, job offers and environmental preservation become growing problems. In the field of food, the process of deterritorialization and loss of knowledge is perceived with the naturalization of practices such as pasteurization of flavors and the disappearance of countless foods, contributing to the degradation of the environment. There has long been talk of a green revolution and sustainability. Thus, this work has as main objective, to point out the contributions of the incentive to the implantation of urban and peri-urban gardens for sustainable development and, consequently, to produce a greener and healthier environment.
\end{abstract}

Keywords: Horta Urbana. Sustainable development. Sustainable Agrifood Systems. Urban Space. 


\section{Introduçáo}

A urbanizaçáo não planejada é um problema recorrente para a humanidade. A

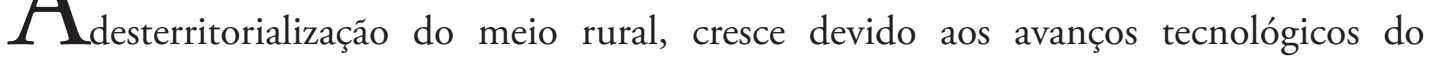
agribusiness, favorecendo o progresso desordenado das áreas urbanas. Entretanto, essa população precisa ser alimentada, porém, para além do abastecimento de alimentos outros problemas recorrentes são a preservação ambiental, bem como, a oferta de empregos.

A relação entre sociedade e meio ambiente vem ganhando espaço tanto na academia quanto nas discussōes da sociedade civil há anos. Desde a revolução verde, muito se discute sobre o fortalecimento de movimentos a favor da sustentabilidade. É notório que os processos de industrializaçấo, cada vez mais fortes e presentes no nosso dia-a-dia, tem trazido as suas irreparáveis consequências ambientais e sociais. De um lado o cultivo de monoculturas que a cada ano são superadas, de outro, a fome que atinge mais de 820 milhóes de pessoas no mundo, segundo dados da ONU.

Sendo assim, repensar a alimentaçáo é fundamental quando se trata de desenvolvimento sustentável. Comer é uma necessidade intrínseca ao ser humano, onde este transforma a natureza para se alimentar, transformação essa que tem gerado consequências drásticas devido a exploração exacerbada do homem. Todavia, o meio ambiente é a integraçáo de natureza externa e seres humanos, porém, o que se vê é a exploraçáo da natureza em detrimento ao "desenvolvimento" almejado pela sociedade capitalista.

Tão comum quanto associar a agricultura ao meio rural é dissociar a possibilidade de que ela aconteça no meio urbano. Contudo, a agricultura urbana não é algo novo, apesar de se apresentar timidamente nestes espaços, tem ganhado visibilidade na academia e na execuçáo de políticas públicas para o seu incentivo como possibilidade de assegurar alimentação para as populaçôes urbanas, garantindo a sua sobrevivência.

Para além da possibilidade de assegurar minimamente o provimento de alimentos, a agricultura urbana envolve também processos sociais, integrando comunidades, aproximandoos da terra e do manejo de insumos, reforçando o entendimento da necessidade de um desenvolvimento sustentável e integrado. Posto isso, o objetivo principal deste trabalho é apontar as contribuiçóes do incentivo à implantação de hortas urbanas e periurbanas para o desenvolvimento sustentável e, consequentemente, produzir um ambiente mais verde e mais saudável.

\section{Desenvolvimento sustentável}

A crise ambiental que emergiu, principalmente enquanto pauta coletiva, a partir da década de 60, gerou a necessidade de discussão do desenvolvimento e suas implicaçóes no meio ambiente (natureza externa e ser humano). Para Foladori (2002) "O próprio conceito de desenvolvimento sustentável nasceu incorporando à sustentabilidade ambiental uma sustentabilidade social e econômica".

O desenvolvimento sustentável, entấo, está baseado neste tripé: social, ambiental e econômico, "os aspectos sociais e econômicos da sustentabilidade sempre complementam os da sustentabilidade ecológica." (FOLADORI, 2002). Sendo assim, dentre os objetivos estáo: 
a redução das desigualdades sociais, promoção do desenvolvimento econômico e exploração controlada dos recursos naturais evitando a degradaçáo ambiental. Desta forma, teoricamente, conserva-se os eixos de produção, reprodução humana e suas atividades, culminando em uma relação harmônica onde mantém-se o crescimento econômico aliado ao controle dos recursos naturais. Porém, sabe-se que isso pouco acontece na prática, onde se fortalece 2 dos pilares do tripé em detrimento de outro.

Para além dos atores sociais, a busca por soluçóes frente à degradação ambiental, deve ser tarefa de toda a comunidade e cada um. Bem sabe-se que a velocidade a qual o ser humano consome o meio ambiente, não tão distante vários recursos podem chegar ao seu limite, colocando em cheque o desenvolvimento econômico táo almejado pelo capitalismo. Portanto, cada um deve assumir o seu papel no que tange a frenagem da degradação ambiental. O relatório de Brundtland (1987) define o desenvolvimento sustentável como "forma como as atuais geraçóes satisfazem as suas necessidades, sem, no entanto, comprometer a capacidade de as geraçóes futuras satisfazerem as suas próprias necessidades".

Neste sentido, de fortalecer os atores locais com o objetivo de estabelecer hábitos sustentáveis, a seguir abordar-se-á o conceito de território e suas implicaçôes no desenvolvimento, principalmente em se tratando do meio rural, alimentação e a forte relação entre produção e consumo.

\section{Território e alimentaçáo}

A alimentação é a mais básica das necessidades humanas, após a respiração e a ingestão de água, ademais tem uma função biológica de nutrição.

A fome biológica distingue-se dos apetites, expressôes dos variáveis desejos humanos e cuja satisfação não obedece apenas ao curto trajeto que vai do prato à boca, mas se materializa em hábitos, costumes, rituais, etiquetas (CARNEIRO, 2003, p. 01).

Sendo assim, o ato de comer envolve outras tantas questóes que estão para além da simples necessidade física de ingestáo de comida. $\mathrm{O}$ que se come, quando se come e com quem se come, são atos, aparentemente, inocentes, ligados à nossa necessidade de alimentação. Porém se unem a sustentabilidade, distinção social e conceito de território. A transformação dos ingredientes para alimentação é algo exclusivamente humano, o que nos distingue de outros animais, sendo assim:

Cozinhar - seja qual for sua modalidade, cotidiana ou exótica - nos situa num lugar muito particular, em que encaramos de um lado o mundo natural e de outro o social. O cozinheiro se encontra justamente entre a natureza e a cultura, conduzindo um processo de tradução e negociação. Tanto a natureza como a cultura são transformadas pelo trabalho. $\mathrm{E}$ ao longo desse processo vi que o mesmo ocorre com o cozinheiro (POLLAN: 2014, p. 25).

Montanari (2013) nos diz que a partir do momento em que o homem e a mulher passam de coletores a produtores, a relação deste com o território muda de maneira decisiva e, consequentemente, gera uma mudança cultural. Lenta e gradativamente a sociedade passa de caçadora coletora a sociedade agricultora. Contanto, comida é cultura: quando produzida, quando preparada e quando consumida, provocando alteraçóes no meio em que vivemos, fazendo da nossa alimentação, espelho da nossa relação com a terra e com os bens materiais. $\mathrm{Ou}$ 
seja, a primeira revolução alimentar se deu através do advento da agricultura.

Nas sociedades agrícolas que ainda existem no mundo, a diversificação dos recursos é o primeiro instrumento para garantir alimento à população local (enquanto as monoculturas, funcionais a indústria alimentícia, são fruto de uma colonização econômica e política que cuida de outros interesses) (MONTANARI: 2013, p. 38).

O campo não deve ser visto apenas como um espaço de produção de mercadorias, mas sim, como um conjunto de fatores sociais, políticos, econômicos e ambientais, os quais caracterizam a diversidade regional e as formas de produção de cada território. O campo é um espaço de produção de vida, "muita gente hoje parece totalmente satisfeita comendo na extremidade da cadeia alimentar industrial sem parar para pensar no assunto" (POLLAN, 2007, p. 43).

Territórios podem ser definidos como lugares de interação entre sociedades humanas e ecossistemas. O território é a maneira como uma determinada sociedade se organiza em sua relação com a natureza. Posto isso, é importante compreender que o meio rural não está restrito à produção agrícola, devendo ser visto pela perspectiva territorial. Onde é possível compreender a diversidade de possibilidades que o rural apresenta, seja como modo de vida ou como espaço agrícola. A relação entre diversas atividades possíveis liga, consequentemente, a produção de alimentos e a gastronomia.

Outra função atribuída à agricultura familiar, a sócio-cultural, significa o resgate de um modo de vida que associa conceitos de cultura, tradição e identidade. $\mathrm{O}$ aumento dos problemas enfrentados pelas populaçóes de grandes cidades tem levado à busca de modos de vida mais saudáveis, à valorização por alimentos produzidos sem o uso de agrotóxicos, por produtos produzidos de forma artesanal, com matéria prima com menor processamento industrial, além de um crescente desejo de um maior contato com a natureza (ALTAFIN, 2007, p.21).

A agricultura deve ser entendida como construção social. A relação com a terra está para além de enxergá-la apenas como meio de produção de mercadorias, mas sim de produção de vida. Segundo Schneider apud Abramovay:

[...] territórios podem ser definidos como lugares de interação entre sociedades humanas e ecossistemas. O território é a maneira como uma determinada sociedade se organiza em sua relação com a natureza. Esta organização supõe formas de coordenação entre organizaçóes sociais, atores econômicos e representantes políticos necessariamente específicas e com uma história própria a cada lugar. No meio rural a noção de território adquire uma dupla importância: em primeiro lugar, ela convida a reflexão sobre o desenvolvimento a voltar-se a um conjunto variado de protagonistas e a superar assim um âmbito estritamente setorial. A diversificação das economias rurais é, portanto, o resultado mais importante do desenvolvimento territorial em áreas não densamente povoadas. Além disso, a noção de território, no meio rural, chama a atenção ao fato de que o processo de desenvolvimento depende fundamentalmente da maneira como cada localidade vai relacionar-se com os ecossistemas em que vive (2004, p. 108).

Sendo assim, para que a sociedade tenha acesso a uma alimentação mais barata, saudável e sustentável, é necessário que esta esteja integrada a produção, seja através da aproximação com a agricultura familiar e o seu fortalecimento, seja através da possibilidade de uma agricultura urbana, excluindo a visão de produção de alimentos exclusivamente aos espaços rurais. 


\section{Sistemas agroalimentares sustentáveis}

A globalização gerou uma massificação de produtos, sabores e culturas, causando a exclusão do meio rural e do "saber fazer" do agricultor. O reconhecimento do meio rural familiar é resistência à dependência generalizada ao sistema convencional. Porém, também é possível desenvolvê-lo nos espaços urbanos, como veremos adiante.

A globalização da crise econômica, o rápido crescimento da população, a migração do campo para a cidade, a deterioração das economias nacionais e as persistentes dificuldades econômicas são condições prévias para o início da atividade de produção de alimentos nas cidades em muitos países em desenvolvimento. Porém a produçáo urbana de alimentos teria uma importância muito menor se não existisse a escassez de oportunidades adequadas e acessíveis para obter renda e uma demanda não satisfeita de produtos agrícolas - em quantidades suficientes e de qualidade adequada nas cidades (DRESCHER; JACOBI; AMEND, 2000, s.p.).

No campo da alimentação, o processo de desterritorialização e de perda de saberes é percebido com a naturalização de práticas como a pasteurização dos sabores e o desaparecimento de inúmeros alimentos. Seguindo a lógica produtivista, grandes conglomerados apropriam-se de terras apenas como mercadoria sob a justificativa de desenvolvimento territorial.

Os estabelecimentos familiares são os principais geradores de postos de trabalho no meio rural. Enquanto estabelecimentos patronais precisam de, em média, 67 hectares para gerar um posto de trabalho, os familiares precisam de apenas oito hectares (INCRA, 2011). Segundo Soares (2002), a função ambiental é um bem público que a agricultura familiar cumpre para a sociedade e deveria ser compensada por isso, ao contrário do que acontece, onde é incentivada ao produtivismo imposto por pacotes tecnológicos.

O direito dos povos de definir suas próprias políticas e estratégias sustentáveis de produçáo, distribuiçáo e consumo de alimentos que garantam o direito à alimentação para toda a população com base na pequena e média produção, respeitando suas culturas e a diversidade de modos camponeses, pesqueiros e indígenas de produção agropecuária, de comercialização e de gestão dos espaços rurais, nos quais a mulher desempenha um papel fundamental. A soberania alimentar favorece a soberania econômica, política e cultural dos povos. Defender a soberania alimentar é reconhecer uma agricultura com camponeses, indígenas e comunidades pesqueiras, vinculadas ao território; prioritariamente orientada a satisfação das necessidades dos mercados locais e nacionais. [...] (Declaração final do Fórum Mundial de Soberania Alimentar, assinada pela Via Campesina, Havana, Cuba/2001, apud LEÃO, 2013, p. 19-20).

Alimentos e hábitos alimentares são a expressão da cultura, memória e história de um povo. A sociedade tem o papel de retomar a busca por alimentos provenientes de uma agricultura que produz com sustentabilidade ambiental e social. É um retorno à memória coletiva pela busca de alimentos limpos e sadios. Apesar da importância do fortalecimento da agricultura familiar, o que pretende-se neste trabalho é vislumbrar as possibilidades do "saber fazer" da agricultura ser inserido nos espaços urbanos, como ferramenta de transformação dos locais onde o crescimento urbano é desordenado e perspectiva de resolução de problemas como alimentação, preservação ambiental e desemprego. 
Para que um mundo mais justo e sustentável se torne realidade, onde globalização seja sinônimo de intercâmbio entre culturas ricas e distintas e não massificação sem rosto. Para que agricultores e pecuaristas voltem a ser donos da terra e não mais assalariados de latifúndios. E para que, ao sentar a mesa de um restaurante, tenhamos a consciência tranquila de que o prato diante de nós não seja fruto da exploração humana ou ambiental (PETRINI, 2009, s.p.).

Necessidade de repensar o consumo - trata-se do consumo estar envolvido em novas dinâmicas e políticas que remetem a valoraçóes do local, da qualidade dos alimentos e da relação do meio urbano com o meio rural. Sendo assim, reavaliar os sistemas agroalimentares os quais são predominantes no nosso território é imprescindível para traçar um caminho sustentável.

\section{Espaço urbano: hortas urbanas e periurbanas}

Ao passo que as cidades crescem, a necessidade de comida também aumenta. A urbanização não planejada gera alguns problemas de abastecimento, para além de degradação ambiental, falta de empregos, condiçóes de vida precárias, principalmente em se tratando de pessoas em vulnerabilidade social. Posto que, a alimentação é algo intrínseco à sobrevivência humana, quais as possibilidades de combater tais problemas?

Em 2001 ocorreu a promulgação da lei 10.257, (BRASIL, 2001), o Estatuto da Cidade, que estabeleceu, em seu artigo $1^{\circ}$ parágrafo único que “[...] o uso da propriedade urbana em prol do bem coletivo, da segurança e do bem-estar dos cidadãos, bem como do equilíbrio ambiental" (BRASIL, 2001). Sendo assim, a apropriação do ambiente de forma coletiva, além de desenvolver práticas que propiciem uma qualidade de vida melhor aos cidadãos, promove saúde e bem-estar (BRASIL, 2001).

O espaço urbano deve ser planejado de maneira a valorizar a escala humana, a fim de que os cidadãos sejam protagonistas dos espaços públicos. É imprescindível que estes espaços atendam às necessidades dos seus habitantes e, não obstante, que as políticas públicas se voltem ao bem-estar do cidadão. Sendo assim, a necessidade de alimentação aliada a integração do indivíduo ao espaço o qual ele habita resulta na possibilidade da execução de hortas urbanas ou agricultura urbana como possibilidade de desenvolvimento sustentável e coesão social.

[Agricultura urbana] consiste na produção e beneficiamento, de forma segura, de produtos agrícolas (hortaliças, frutas, plantas medicinais, ornamentais) e pecuários (animais de pequeno, médio e grande porte).

Esses produtos são utilizados para o consumo próprio, trocas, doações el oucomercialização, e (re)aproveitam, de forma eficiente e sustentável, os recursos e insumos locais (solo, água, resíduos, mão de obra, saberes, etc). A prática da agricultura urbana acontece no espaço urbano, como quintais, lotes vagos, áreas verdes/vazios urbanos, áreas institucionais, terrenos arrendados ou emprestados, etc (CEPAGRO, 2009, p. 17).

A agricultura urbana é uma forma de provisão de alimentos. As hortas urbanas representam assim uma segurança alimentar perante uma crise econômica, com o aumento do preço dos produtos, e/ou outras crises que possam interferir no abastecimento, além de proporcionar autonomia aos cidadáos. Contudo, podemos citar Lefebvre quando define o direito à cidade, que "significa o direito dos cidadãos-citadinos e dos grupos que eles constituem (sobre a base das relaçôes sociais) de figurar sobre todas as redes e circuitos de comunicação, de informação, 
de trocas".

[...] A agricultura urbana é praticada dentro (intra-urbana) ou na periferia (periurbana) dos centros urbanos (sejam eles pequenas localidades, cidades ou até megalópoles), onde cultiva, produz, cria, processa e distribui uma variedade de produtos alimentícios e não alimentícios, (re)utiliza largamente os recursos humanos e materiais e os produtos e serviços encontrados dentro e em torno da área urbana, e por sua vez, oferece recursos humanos e materiais, produtos e serviços para uma mesma área urbana (MOUGEOT, 2000, s.p.).

Como bem coloca o autor, a agricultura urbana deve estar integrada ao "ecossistema urbano", interagindo com os seus elementos espaciais. Contudo, é válido ressaltar que a agricultura urbana traz inúmeros benefícios nos locais onde é colocada em prática. Pois, para além da possibilidade de servir como fonte de renda para as famílias, muitas vezes, quando a produção não é comercializada, acaba sendo consumida o que gera uma grande economia evitando a necessidade de compra dos insumos produzidos.

$\mathrm{Na}$ América Latina, a expansão urbana tem gerado uma crescente insegurança alimentar nas cidades e em sua periferia, particularmente entre os setores populacionais vítimas da pobreza e da extrema pobreza. A situação é crítica por causa da alta volatilidade nos preços dos alimentos e do impacto da recessão econômica e do desemprego. É importante notar que os pobres gastam mais de $50 \%$ de seus rendimentos para comprar os alimentos de que precisam (FAO; MDS; IPES; RUAF, s.p.)

Sendo assim, a possibilidade de desenvolvimento de umaagricultura urbana pode contribuir fortemente para a segurança alimentar, principalmente de populaçóes em vulnerabilidade social. Em se tratando do conjunto de possibilidades do desenvolvimento sustentável, a agricultura urbana auxilia no enverdecimento das cidades e no equilíbrio ambiental.

E ainda, na escala das grandes cidades, a agricultura urbana limpa o ar e devolve o carbono ao solo. Colabora com os microclimas, conserva os recursos hídricos urbanos (em alguns casos, pois pode degradá-los em outros), e mantém uma superfície permeável entre o ar e o solo. [...] $\mathrm{Na}$ escala das pequenas comunidades, a agricultura urbana pode melhorar a "paisagem vital", porém também pode, se mal praticada, contaminar o ambiente e debilitar a saúde humana (SMIT, 2000).

Posto isso, é válido ressaltar o importante papel que pode ser desenvolvido pela agricultura urbana e periurbana dentro da estrutura das cidades. Para além de contribuir para a paisagem, para o desenvolvimento sustentável, o incentivo a agricultura urbana gera renda, permite o acesso a alimentos de baixo custo e de qualidade e dá suporte a uma população, historicamente, deixada à margem do mercado de trabalho formal. Ocupar os espaços urbanos com inteligência para gerar produtos agrícolas saudáveis para os cidadãos, promover trabalho e renda e combater a miséria certamente podem ser elencados como objetivos da agricultura urbana.

Em termos de sua contribuição para o desenvolvimento, a agricultura urbana aumenta a segurança alimentar, gera renda adicional e emprego para os residentes urbanos pobres e de classe média, e contribui para um ambiente urbano ecologicamente saudável (ZEEUW, GÜNDEL e WAIBEL, 2000, s.p)

Entretanto, "o acesso aos recursos da terra e água, assim como a segurança dos direitos dos usuários e o nível de preços dos lotes de terra são fatores cruciais para o desenvolvimento da agricultura urbana” ZEEUW, GÜNDEL e WAIBEL (2000). Por isso mesmo são necessárias 
políticas de uso do solo, de segurança alimentar urbana, de saúde, ambientais e de desenvolvimento social. Por fim, é importante ressaltar que a agricultura urbana, é uma criadora de coesão social, devido ao modelo a qual se insere, por sua estrutura produtiva e ao comércio a qual se vincula, permitindo o contato direto entre produtores e consumidores.

\section{Consideraçóes finais}

Para muito além de compreender de que maneira o ser humano se alimenta, analisar os entrelaçamentos entre consumo e produção podem nos trazer informaçóes importantes sobre cultura, sociedade, territórios, política etc., permitindo identificar como as sociedades se organizam, vivem, compreendem a alimentação e, consequentemente, se relacionam com o meio ambiente. Quando se trata de agricultura urbana, pode-se observar com esta pesquisa, que no Brasil ainda há muito a ser desenvolvido, apesar de já existirem muitos projetos que movimentam os espaços urbanos, o incentivo através de políticas públicas e investimentos se fazem necessários.

O crescimento desordenado das cidades, aliado ao esvaziamento do meio rural, devido às condições impostas pela agricultura patronal, gera inúmeros problemas como degradação ambiental e insegurança alimentar. Promover o desenvolvimento da agricultura urbana, pode ser uma grande chance de minimizá-los, além de promover uma coesão social. A agricultura urbana permite relacionar desenvolvimento sustentável, geração de renda, oferta de empregos, mudança nas paisagens locais, enverdecimentos das cidades, segurança alimentar, direito à cidade e fortalecimento de pequenas comunidades. Certamente deve ser utilizada como ferramenta para um crescimento sustentável sendo incentivada e promovida por políticas públicas.

\section{Referências}

ALTAFIN, I. Reflexóes Sobre o Conceito de Agricultura Familiar. Disponível em: http:// www.enfoc.org.br/system/arquivos/documentos/70/f1282reflexoes-sobre-o-conceito-deagricultura-familiar---iara-altafin---2007.pdf. Acesso em: 04/11/2020.

BARBER, Dan. O terceiro prato: notas de campo sobre o futuro da comida. Rio de Janeiro: Bicicleta Amarela, 2015. 478 p.

BRASIL. Secretaria Especial de Agricultura Familiar e Desenvolvimento Agrário. Disponível em: http://www.mda.gov.br . Acesso em: 04/11/2020.

BRASIL. Emater/RS - ASCAR. Disponível em: http://www.emater.tche.br . Acesso em: $10 / 06 / 2020$.

CARNEIRO, Henrique. Comida e Sociedade: uma história da alimentação. Rio de Janeiro: Elsevier, 2003.

CAPORAL, F. R.; COSTABEBER, J. A. Agroecologia e extensão rural: contribuições para a promoção do desenvolvimento rural. Porto Alegre, 2004. Disponível em: http:// www.emater.tche.br/site/arquivos_pdf/teses/agroecologia\%20e\%20extensao\%20rural $\% 20$ contribuicoes $\% 20$ para $\% 20$ a $\% 20$ promocao $\% 20$ de $\% 20$ desenvolvimento $\% 20$ rural $\% 20$ sustentavel.pdf. Acesso em: 16/11/2020. 
CEPAGRO. Cartilha de Agricultura urbana. Florianópolis, 2009.

DRESCHER, A. W.; JACOBI, P.; AMEND, J. Segurança alimentar urbana: agricultura urbana, uma resposta à crise? Revista de Agricultura Urbana, Lima, n.1, 2000.

GASQUES, José Garcia; CONCEIÇÃO, Júnia Cristina P. R. da; FERREIRA, Brancolina et al. Transformaçóes da agricultura e políticas públicas. Brasília: IPEA, 2001.

LEÃO, M. O direito humano à alimentação adequada e o Sistema Nacional de Segurança Alimentar e Nutricional. Brasília: ABRANDH, 2013.

MONTANARI, M. A fome e a abundância: história da alimentação na Europa. Bauru: EDUSC, 2003. 270 p.

MONTANARI, M. Comida como cultura. São Paulo: Senac São Paulo, 2013. 207p.

MONTANARI, M. (Org). O mundo na cozinha: história, identidade, trocas. São Paulo: Estação Liberdade; Senac, 2009. 255p.

MOUGEOT, L. J. A. Agricultura urbana: conceito e definição. Revista de Agricultura Urbana, n.1, 2000..

PETRINI, Carlo. Slow Food: princípios da nova gastronomia. São Paulo: SENAC, 2009. 245p.

POLLAN, Michael. Cozinhar: uma história natural de transformação. Rio de Janeiro: Intrínseca, 2014. 448 p.

SENADO FEDERAL. Do Ecodesenvolvimento ao Desenvolvimento Sustentável no Relatório Brundtland. Disponível em:<http://www.senado.gov.br/noticias/Jornal/ emdiscussao/rio20/temas-em-discussao-na-rio20/ecodesenvolvimento-conceitodesenvolvimento-sustentavel-relatorio-brundtland-onu-crescimento-economico-pobrezaconsumo-energia-recursos-ambientais-poluicao.aspx>. Acesso em: 10/11/2020.

SMIT, J. Agricultura urbana e biodiversidade: urbanização e redução da biodiversidade. Revista de Agricultura Urbana, n.1, 2000.

SHNEIDER, Sérgio. A abordagem territorial do desenvolvimento rural e suas articulaçóes externas. ISSN 1807-0337

OHMAE, K. The Borderless World: Power and Strategy in the Interlinked Economy. Nova York, Harper end Row, 1990.

ZEEUW, H. de; GÜNDEL, S.; WAIBEL, H. A integração da agricultura urbana nas políticas públicas. Revista de Agricultura Urbana, n.1, 2000. 